\title{
Patient Education and Adherence to Aerosol Therapy
}

\author{
Arzu Ari PhD RRT PT CPFT FAARC
}

\author{
Introduction \\ Problems With Patient Education and Adherence to Aerosol Therapy \\ Factors Affecting Patient Adherence to Prescribed Aerosol Therapy \\ The Device \\ The Drug and Dosing \\ The Patient \\ The Health-Care Professional \\ Effective Educational Interventions in Patient Adherence \\ Preparing One-on-One Individualized Education Sessions \\ Choosing an Aerosol Device Based on Patient Preference \\ Keeping the Aerosol Device Consistent \\ Providing Effective Instructions \\ Developing Psychomotor Skills of Patients With Teaching Devices \\ Preparing Personalized Inhaler Technique Labels \\ Following Up With Patients After Prescribed Aerosol Therapy \\ Assessment of Inhalation Technique \\ Aerosol Inhalation Monitor \\ In-Check DIAL \\ Inhalation Manager \\ Mag-Flo Inhaler \\ 2Tone Trainer \\ Turbutest \\ Monitoring Patient Adherence to Prescribed Aerosol Therapy \\ Patient Self-Reports or Diary Cards \\ Clinical Judgment \\ Pharmacy Data \\ Biologic Measures \\ Electronic Device Monitoring \\ Promoting Patient Adherence to Aerosol Therapy \\ Understanding Health-Related Behavior \\ Preparing Patients and Their Caregivers \\ Promoting the Patient-Physician Relationship \\ Promoting the Role of Respiratory Therapists and Other Health-Care \\ Establishing Patient-Centered Teamwork in Aerosol Medicine \\ Working with Policymakers to Resolve Problems With Patient Educa- \\ tion and Adherence \\ Summary
}

Nonadherence to prescribed medications results in disease instability and poor clinical control, with increases in hospital admissions, emergency room visits, school/work absenteeism, morbidity, and mortality. Poor patient adherence to therapy can be due to lack of cognition, competence, or contrivance. Patients who have not been trained or fail to understand use of drug and device combinations (cognition) often do not have the ability to use an aerosol device correctly (competence). Many patients have the competence to use the device correctly and know why they should 
use the device in the way they were taught; however, they still contrive to use it in an ineffective and suboptimal manner that reduces its efficiency and effectiveness. Ensuring effective aerosol therapy and optimizing its role in disease management involve not only delivery of aerosolized medications to the lungs, but also understanding why, when, and how to use the medications, competence to use the device, motivation to adhere to therapy, and not contriving to use the device in a way that will prevent effective drug delivery. This paper explains some of the problems with patient education and adherence to aerosol therapy and suggests strategies to evaluate, monitor, and improve patient adherence effectively in primary care. Factors affecting patient adherence to prescribed medications, effective educational interventions, and strategies to promote patient adherence to aerosol therapy are also discussed. Key words: patient education; patient adherence; aerosol therapy; inhaled medications; metered-dose inhalers; nebulizers; dry powder inhalers. [Respir Care 2015;60(6):941-957. (C) 2015 Daedalus Enterprises]

\section{Introduction}

Effective aerosol therapy and disease management involve not only ensuring delivery of aerosolized medications to the lungs, but also patient cognition of how, why, and when to administer, competence to use the device in an effective manner, and not contriving to use the device in a way that will prevent effective drug delivery. ${ }^{1}$ Three key terms describe how well a patient follows a prescribed aerosol therapy: (1) adherence, (2) compliance, and (3) contrivance. Although these terms describe the level of agreement between a patient's actions and therapy with prescribed medications, there are slight differences in their definitions. For example, compliance means that patients follows their prescriptions as directed, whereas the term adherence means that patients take their medications in the most accurate manner during their prescribed therapy. ${ }^{1,2}$ In contrivance, patients do what they want, when they want, and how they want. Although patients may have exhibited the competence to use the device correctly, they use it in a manner that they think better meets their needs. By doing so, they may fail to achieve effective and consistent delivery of prescribed medications to the lungs needed for positive clinical outcomes. ${ }^{3}$ Contrivance can be an issue with all types of aerosol devices. Some patients and parents understand how and why a pressurized metered-dose

Dr Ari is affiliated with the Department of Respiratory Therapy, Georgia State University, Atlanta, Georgia.

Dr Ari presented a version of this paper at the 53rd RESPIRATORY CARE Journal Conference, "Aerosol Drug Delivery in Respiratory Care," held June 6 and 7, 2014, in St Petersburg, Florida.

Dr Ari has disclosed a relationship with Aerogen.

Correspondence: Arzu Ari PhD RRT PT CPFT FAARC, Department of Respiratory Therapy, Georgia State University, PO Box 4019, Atlanta, GA 30302-4019. E-mail: arzuari@ hotmail.com.

DOI: $10.4187 /$ respcare. 03854 inhaler (pMDI) should be used with a valved holding chamber to achieve effective aerosol therapy; however, they prefer to use it in a suboptimal manner. The majority of patients $(65-73 \%)$ use a pMDI alone despite the fact that they are prescribed a valved holding chamber for use and shown the correct technique. ${ }^{1,4}$ Some patients choose to inhale rapidly with pMDIs and slowly with dry powder inhalers (DPIs) even though they demonstrated good techniques during training. Others may stop inhaling when a breath-actuated pMDI is triggered with inspiration. Although contrivance is an important issue for patient adherence to aerosol therapy, it is seldom discussed in the literature. It is important to understand these concepts to help ensure clinical therapeutic effect and reduce health-care resource use, morbidity, and mortality. This paper explains problems with patient education and adherence to aerosol therapy and suggests ways to effectively evaluate, monitor, and improve patient adherence in primary care. Factors affecting patient adherence to prescribed medications, effective educational interventions, and strategies to promote patient adherence to aerosol therapy are also discussed.

\section{Problems With Patient Education and Adherence to Aerosol Therapy}

Patient adherence to prescribed aerosol therapy is important in the treatment of pulmonary diseases. Previous research has shown that nonadherence results in poor clinical control and increases school and work absenteeism, unscheduled health-care utilization, morbidity, and mortality. ${ }^{5-11}$ Vestbo et $\mathrm{al}^{6}$ reported a strong association between poor adherence to prescribed inhaled medications and risk of hospital admission due to exacerbations. There is a strong inverse relationship between adherence to inhaled medications and mortality in patients with COPD. The mortality of subjects who were adherent to therapy was 2 times less compared with subjects who were not. ${ }^{6}$

Nonadherence to prescribed inhaled medications is also associated with increased health-care cost. The cost of 
Table 1. Factors Affecting Patient Adherence to Prescribed Aerosol Therapy

\begin{tabular}{|c|c|}
\hline Parameter & Factors \\
\hline Device & $\begin{array}{l}\text { Complexity of aerosol therapy with prescribed device, combination of aerosol devices for therapy (eg, nebulizer } \\
\text { for one drug and pMDI for another) }\end{array}$ \\
\hline Drug and dosing & No. of medications to be taken, dosing frequency, combination formulations of inhaled drugs \\
\hline \multirow[t]{2}{*}{ Patient } & $\begin{array}{l}\text { Unintentional: patient does not correctly understand therapy, misunderstands prescribed drug regimen (poor } \\
\text { physician-patient communication), incorrect aerosol device technique, language barriers }\end{array}$ \\
\hline & $\begin{array}{l}\text { Intentional: patient understands therapy but does not adhere correctly, beliefs (eg, I do not really require regular } \\
\text { medication; I am not really sick; I gain attention from parents and am kept at home [children]; the medication } \\
\text { is too expensive; I have concern about adverse effects; I do not perceive an effect from the medication), } \\
\text { forgetfulness, stress and busy lifestyle, complex and demanding aerosol regimen, psychological factors (eg, } \\
\text { depression) }\end{array}$ \\
\hline Health-care professional & $\begin{array}{l}\text { Inadequate knowledge of inhaler function and correct use, lack of understanding of the importance of having a } \\
\text { partnership with the patient, inability to communicate with the patient, lack of recognition of patient barriers } \\
\text { to adherence (eg, language, cognitive, or psychological) }\end{array}$ \\
\hline
\end{tabular}

pMDI $=$ pressurized metered-dose inhaler

nonadherence by patients with chronic diseases is estimated to be $\$ 300$ billion/y in the United States. ${ }^{12}$ According to previous research, the adherence rate of subjects with COPD is $>50 \%^{13-18}$ as opposed to $30-70 \%$ in subjects with asthma. ${ }^{19}$ Patient adherence tends to be lower in the evening and declines over time. ${ }^{14,20-22}$ Jónasson et al23 determined the mean adherence rates of 122 children 7 to $16 \mathrm{y}$ of age over a 27-month period using an electronic device monitor. Their findings showed that the mean adherence rate at 3 months was $76.7 \%$ compared with $44 \%$ by end of the study. Use patterns of prescribed inhaled medications tend to be sporadic. In a 5-y study, Haupt et al ${ }^{14}$ revealed that $51 \%$ of subjects with obstructive lung diseases acquired their prescribed medications less than once/y. Jung et $\mathrm{al}^{22}$ studied adherence to prescribed medications in 11,376 subjects with COPD who were $\geq 60 \mathrm{y}$ of age and reported that $52 \%$ used some of their prescribed medications and that only $28 \%$ had satisfactory refill patterns of their inhaled corticosteroids.

Although many patients may understand the importance of adherence to prescribed medications, they may still struggle with correct use of aerosol devices during their therapy. The reported prevalence of incorrect inhalation technique varies from 4 to $94 \% .^{10,24-27}$ There are many reasons behind incorrect inhalation technique. Patients may be confused with devices requiring different inhalation techniques or have difficulty using their aerosol devices correctly. They may not be able to learn how to use their device correctly due to low literacy level, inadequate time and information to learn, poor attention span (especially when sick), and lack of follow-up. Many issues with incorrect inhalation technique can be solved through patient education given by health-care professionals. However, lack of clinician time and resources combined with limited financial incentives for patient education remains an issue. In addition, many studies in the literature have shown that physicians and health-care professionals frequently do not know how to use aerosol devices correctly. ${ }^{28-32}$

\section{Factors Affecting Patient Adherence to Prescribed Aerosol Therapy}

Many factors influence subject adherence to prescribed aerosol therapy. ${ }^{33}$ As shown in Table 1, these factors can be divided into 4 categories: (1) the device, (2) the drug and dosing, (3) the patient, and (4) the health-care professional.

The Device. As evidenced by many studies in the literature, optimum use of current aerosol devices is deceptively difficult. ${ }^{27,34-40}$ Unfortunately, the needs and capabilities of patients are not always adequately considered during device development, resulting in a variety of aerosol devices that fail to meet the needs of many patients with pulmonary diseases. It is important to use an aerosol device that generates drug particles in the respirable range $(1-5 \mu \mathrm{m})$ to maximize aerosol delivery to the lungs. Although current aerosol devices can produce aerosols in the respirable range, most patients cannot achieve the depth and speed of inhalation required by the device. For instance, older patients with COPD have difficulty using a range of aerosol devices effectively because of their comorbidities and cognitive and physical impairments, ${ }^{11}$ which may lead to many errors in the use of each aerosol device. Table 2 lists common errors in the use of aerosol devices by patients with pulmonary diseases. Manufacturing and pharmaceutical companies now realize that addressing the needs and abilities of patients and producing a device that generates a respirable range in a given dose are important. Rubin and Durotoye ${ }^{41}$ found that many subjects used pMDIs after the medication was depleted because they did not know how to recognize an empty pMDI, 
Patient Education and Adherence to Aerosol Therapy

Table 2. Most Common Errors With Aerosol Devices Used in the Treatment of Patients With Pulmonary Diseases

\begin{tabular}{ll}
\hline \hline \multicolumn{1}{c}{ Aerosol Device } & Most Common Errors \\
\hline Traditional pMDIs & $\begin{array}{c}\text { Lack of hand-breath coordination, inhaling too rapidly, stopping the inhalation as soon as the } \\
\text { aerosol hits the pharynx, failing to hold the breath after inhalation } \\
\text { Inhaling too rapidly, stopping the inhalation as soon as the aerosol hits the pharynx }\end{array}$ \\
$\begin{array}{l}\text { Breath-Actuated pMDIs } \\
\text { FPIs }\end{array}$ & $\begin{array}{l}\text { Failing to prime the device, using the device after it is empty, exhaling through the device } \\
\text { before inhalation, failing to inhale forcefully }\end{array}$
\end{tabular}

$\overline{\text { pMDIs }=\text { pressurized }}$ metered-dose inhalers

DPIs $=$ dry powder inhalers

and they continued to actuate the pMDI as long as they heard the sound of aerosol escaping. Therefore, $74 \%$ of subjects continued to actuate up to twice the number of actuations available in the device and did not receive more than one third of all doses. Rubin and Durotoye ${ }^{41}$ also reported a variation between pMDI canisters and that pMDI canister flotation in water provided inaccurate information about the amount of drug remaining in the device. Moreover, using the flotation technique with pMDIs may cause occlusion of the canister valve with water droplets. Recent improvements are aerosol devices with built-in features that provide feedback to help patients use the devices correctly and instill confidence that the dose has been inhaled.

The Drug and Dosing. Patient adherence to prescribed medications has been associated with the frequency, type, and number of drugs to be taken, as well as the type of aerosol devices used to administer prescribed medications. Previous research showed a relationship between subject adherence and the frequency with which a drug must be taken. ${ }^{42-44}$ Patient adherence declines with the increasing frequency of medication use; therefore, clinicians should consider selecting a drug option that makes dosing more convenient by reducing the frequency and number of doses given to patients, modifying dosing to fit patients' schedules, and incorporating medication administration into mealtimes and before bedtime. By doing this, they may increase patient adherence to prescribed medications. ${ }^{21,45}$

Combining aerosolized medications into one formulation reduces the complexity of drug administration because it decreases the number of aerosol therapy sessions with prescribed medications. Stoloff et a ${ }^{46}$ compared medication-refill data with (1) the combination of fluticasone propionate and salmeterol in a single inhaler, (2) separate inhalation of fluticasone propionate and salmeterol from 2 inhalers, (3) inhaled fluticasone propionate and oral montelukast taken together, and (4) fluticasone propionate and montelukast taken separately. They reported that subjects using fluticasone propionate and salmeterol from a single inhaler had significantly better adherence than the other groups that participated in this study. Sovani et al ${ }^{47}$ also conducted a study to determine the effect of using a single inhaler containing a long-acting $\beta_{2}$ agonist and a corticosteroid on subject adherence with inhaled corticosteroids. They randomized 71 subjects into control and treatment groups ( 35 and 36 subjects, respectively). The control group received budesonide (200 $\mu \mathrm{g}$, one puff twice daily) in addition to a short-acting $\beta_{2}$ agonist as required, while the treatment group received budesonide/formoterol (200/ $6 \mu \mathrm{g}$ ). Similar to Stoloff et al, ${ }^{46}$ Sovani et al ${ }^{47}$ also found that subjects using a single inhaler had a better adherence rate than those in the control group ( $80 \%$ vs $60 \%)$.

Additionally, subject adherence to prescribed $\beta$ agonists is less of an issue compared with corticosteroids. ${ }^{9,21,48} \mathrm{Al}$ though inhaled corticosteroids are safe and efficacious, subjects in all age groups have poor adherence to these medications. ${ }^{49}$ Using the pMDI chronolog, Milgrom et al ${ }^{9}$ found that adherence to inhaled corticosteroids in children with asthma was $32 \%$, whereas it was $48 \%$ for $\beta_{2}$ agonists. The authors reported that $25 \%$ of subjects did not take inhaled corticosteroids $>60 \%$ of the time of the study. Three main barriers influence adherence to prescribed corticosteroids. First, patients think that they do not need corticosteroids because they believe that reliever medications provide adequate control of their disease due to the immediate effect experienced after use. Second, some patients believe that inhaled corticosteroids will not help them control their diseases. Third, patients refuse to take inhaled corticosteroids due to their fear of adverse effects and drug dependence. Finally, patients sometimes stop using prescribed medications because they believe that their health status has improved.50,51

The Patient. Each patient is affected by his or her ability, beliefs, knowledge, mood, attitudes, and motivation regarding disease and treatment. ${ }^{52,53}$ Although factors such as age, marital status, socioeconomic status, and education level also play a role in patient adherence to aerosol therapy, they do not provide obvious predictors. ${ }^{19,54,55}$ On the other hand, depression is an important factor causing nonadherence to prescribed medication and poor disease management in patients with pulmonary disorders such as COPD. ${ }^{56-58}$ Previous research has shown that adherence to 
prescribed medication is an issue especially in low-income and minority subjects. .9-61 $^{59}$

Lack of adherence is divided into 2 categories: (1) unintentional nonadherence and (2) intentional nonadherence. Patients showing unintentional nonadherence have a lack of information or a misunderstanding about the prescribed therapy, the correct technique with their prescribed aerosol device, and/or have language barriers. Therefore, they are unaware that they do not adhere to aerosol therapy and fail to understand the correct use of aerosol devices for the treatment of pulmonary diseases. In contrast, patients showing intentional nonadherence understand the importance of prescribed therapy but reject the diagnosis, treatment, or both. They do not take their prescribed medications because of their beliefs, stress, busy lifestyle, inability to afford medications, forgetfulness, or fear of adverse effects. ${ }^{62}$ Some patients do not take their medications because of a misconception of their health status, the cost of medication, or secondary gain of children such as attention from parents. ${ }^{62,63}$ Many patients with intentional nonadherence who do not believe that their disease is serious enough to require long-term therapy eventually progress to severe disease. ${ }^{16,52,62,63}$ Some patients reduce the frequency of doses prescribed by their doctors, and others stop taking their medications when there is a decline in symptoms. ${ }^{51}$ Others are concerned about developing a tolerance to the inhaled medications with regular use and that over time the medication will be ineffective in an emergency such as during exacerbations. ${ }^{61}$ Although some patients refuse to take medications due to side effects, others may have unrealistic expectations of their medications. ${ }^{62,63}$ Table 1 lists general types of nonadherence to prescribed aerosol therapy and potential factors that can predispose patients to intentional and unintentional nonadherence.

The Health-Care Professional. Problems with healthcare professionals start with inappropriate device selection but ultimately center around their inability to provide patient education, including lack of familiarity with use of specific devices, inadequate time to teach, poor training techniques, and lack of materials on aerosol therapy. Unfortunately, the knowledge and understanding of healthcare professionals have been shown to be poor, except for those clinicians with a specific interest in aerosol medicine; therefore, only a minority of health-care practitioners know the correct way to use aerosol devices. ${ }^{28-32,64}$ Proper teaching by health-care professionals is crucial for optimum use of most inhalers. ${ }^{5,65}$ Therefore, health-care professionals need to brush up on their skills and use every opportunity to teach and reinforce proper use of inhaled medications across the health-care continuum.

\section{Effective Educational Interventions in Patient Adherence}

Even when patients have an adequate understanding of how to use an aerosol device correctly, they often will not be able to use the device without effective instructions. In a meta-analysis of 32 studies with 3,706 participants from 2 to $18 \mathrm{y}$ of age, Guevara et al ${ }^{66}$ showed that effective educational interventions reduced school absenteeism, sleep alterations, number of emergency room visits, and morbidity due to asthma. Strategies that help clinicians individualize patient education in aerosol therapy are: (1) provide one-on-one individualized training, (2) use a device preferred by the patient, (3) keep the device consistent, (4) provide effective instructions, (5) develop psychomotor skills of patients with teaching devices, (6) prepare personalized inhaler technique labels, and (7) follow-up with patients to check the inhaler technique.

Preparing One-on-One Individualized Education Sessions. A one-on-one training session is more effective than a large-group lecture in terms of individualizing the education session to a specific patient and motivation to adhere to prescribed medications through open-ended questions, affirmations, reflective listening, and summary statements. Previous research has shown that individualized patient education sessions increase medication adherence and improve clinical outcomes. ${ }^{67,68}$ Janson et al ${ }^{68}$ conducted a randomized controlled trial with subjects with moderate-to-severe asthma to determine the effect of an individualized self-management education program on medication adherence and markers of asthma control over a 24-week period. Subjects were randomly assigned to either usual care with self-monitoring alone or an individualized education program that included training on asthma and correct inhalation technique in addition to selfmonitoring of symptoms and peak flow. They found that subjects who received individualized education sessions had higher medication adherence compared with the control group. Nighttime awakening and $\beta$-agonist use also significantly decreased in the intervention group. Each patient education session should include: (1) basic facts about the patient's disease, (2) the role of medications, (3) the skills needed to use aerosol devices, (4) monitoring disease symptoms, (5) daily self-assessment to monitor conditions, and (6) an action plan to respond to exacerbations.

Choosing an Aerosol Device Based on Patient Preference. Patient preference is linked to the ability to properly perform the inhalation technique with the device and a greater degree of satisfaction with therapy. ${ }^{69,70}$ Therefore, using an aerosol device that is preferred by the patient is an important component of patient education in aerosol therapy. Factors such as ease of use, portability, 


\section{Patient Education and Adherence to Aerosol Therapy}

size, noise, taste, and cost may influence a patient's preference. A recent study showed that ease of use, dose recording, and dose capacity (single or multidose) are important features to have in an aerosol device. ${ }^{71}$ Several factors were associated with ease of use, including fewer steps to operate the inhaler, confirmation that the dose had been taken correctly, easier coordination of breathing maneuvers, and less resistance during inhalation. ${ }^{71}$ Although one assumes that increased patient satisfaction will lead to an improvement in patient adherence and clinical outcomes and a reduction in health-care cost, research on these associations is still lacking.

Keeping the Aerosol Device Consistent. When patients are prescribed more than one type of device with the prescribed medications, they may become confused because of the different techniques required for each device. ${ }^{72}$ Therefore, using the same type of aerosol device for different inhaled medications may increase the patient's adherence to aerosol therapy. ${ }^{72-75}$

Providing Effective Instructions. Use of written instructions alone is not sufficient for effective patient education in aerosol therapy. Therefore, an effective patient education program should include both written and verbal instructions, as well as demonstrations and practice. The written instructions should be short, clear, and easily understood by patients and caregivers. Writing instructions at or below a sixth-grade reading level and including pictures and illustrations may help improve patients' comprehension and compliance with therapy. ${ }^{76}$ Also, demonstrating each step of the correct technique during the education session can help overcome language barriers between the patient and health-care provider. ${ }^{77}$ Clinicians should provide repeated instructions during patient education sessions to ensure that patients understand therapy and improve patient adherence to prescribed medications. Takemura et $\mathrm{al}^{78}$ determined factors that contribute to patient adherence to aerosol therapy and examined their relationship with quality of life in 88 subjects with COPD using the St George Respiratory Questionnaire. With a response rate of $63 \%$, the authors reported that receiving repeated instructions about inhalation techniques was the only significant factor associated with patient adherence to aerosol therapy.

\section{Developing Psychomotor Skills of Patients With Teach-}

ing Devices. It is essential to develop the psychomotor skills of patients in each training session so that they can use aerosol devices in the most correct and efficient manner. Table 3 lists general principles in teaching psychomotor skills to patients. ${ }^{11}$ Health-care professionals should use simple teaching devices with or without placebo to
Table 3. General Principles in Teaching Psychomotor Skills to Patients

Conduct a demonstration of inhaler technique, verbally describing each step

Repeat the demonstration without explanation

Repeat again with verbal comments

Have the patient demonstrate the maneuver

Identify problems with the patient's technique

Repeat the instruction and have the patient demonstrate again

Ask the patient to verbalize most of the aspects of the procedure and

those she or he finds most troublesome

Arrange a follow-up instruction

Remind the patient to bring his or her inhalers and spacers to every appointment

Provide instruction to family and friends

Review and dispense instructional leaflets, if available

From Reference 12, with permission.

Table 4. Evaluation Template That Can Be Used in Follow-Up Sessions

Devices being used for treatment: appropriateness of device for patient, reliable performance

Patient's knowledge: prescribed drug, benefits of aerosol therapy, and reasons for special breathing techniques

Breathing technique: slow or fast, breath-hold before exhalation

Daily treatment plan

Patient's adherence to aerosol therapy

develop the psychomotor skills of the patient needed for the device.

Preparing Personalized Inhaler Technique Labels. Patients are not usually aware of their incorrect technique and do not ask health-care professions for more information. Preparing personalized inhaler technique labels and highlighting incorrect steps on the label are low-cost feasible interventions that can be used as a strategy for patient education and adherence to aerosol therapy. ${ }^{79}$

Following Up With Patients After Prescribed Aerosol Therapy. Following up with patients and their caregivers is an important component of effective educational intervention in aerosol therapy. Follow-ups enable healthcare professionals to answer any questions that patients may have, correct mistakes in their aerosol device technique, and ensure patients' understanding of prescribed medications and treatments. Because a patient's knowledge and understanding of aerosol therapy have an impact on adherence to therapy, the follow-up sessions should include a time for assessment and training. Table 4 shows an evaluation template that clinicians can use in follow-up sessions. Although health-care professionals prepare ef- 


\section{Patient Education and Adherence to Aerosol Therapy}
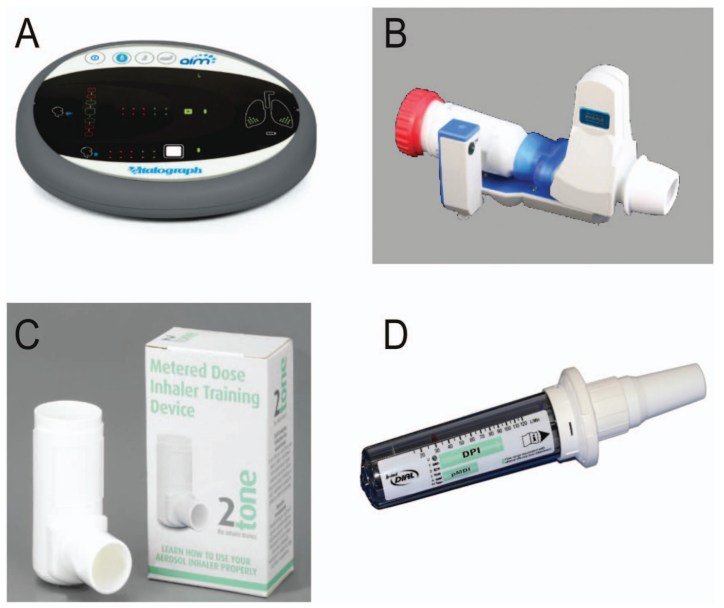

Fig. 1. Commercially available devices that are used to assess inhalation techniques of patients who are prescribed aerosolized medications. A: Vitalograph AIM, courtesy Vitalograph. B: MagFlo, courtesy Fyne Dynamics. C: 2Tone Trainer, courtesy DynamiTech. D: In-Check DIAL, courtesy Clement Clarke International.

fective follow-up visits after treatment, nonattendance can be an issue in aerosol therapy. Contacting patients to remind them about their scheduled appointments reduced nonattendance at a diabetic clinic from 15 to $4.6 \% .^{80}$ This simple strategy can be used by health-care professionals to improve nonattendance in follow-up visits and may improve adherence to aerosol therapy.

\section{Assessment of Inhalation Technique}

Nebulizers, pMDIs, and DPIs are commonly used in the treatment of patients with pulmonary diseases. However, it is sometimes difficult to use a particular device due to a patient's age, disability, and inadequate lung function; therefore, evaluation of patient performance is necessary to achieve therapeutic goals determined for disease management. There are several devices that are used to assess inhalation techniques (Fig. 1). Although these devices provide an objective evaluation of the inhalation technique, it is important to note that they cannot assess the patient's preparation and handling of the device..$^{81}$

Aerosol Inhalation Monitor (AIM). As an electronic pMDI trainer, the Vitalograph AIM (Vitalograph, Lenexa, Kansas) measures inspiratory flow and monitors patient hand-breath coordination during pMDI usage. This device includes a pMDI with placebo that has a sensitive flow transducer that detects flow with the beginning of inspiration. A green light indicates correct inhalation technique, and a red light indicated that the patient's inhalation technique was not accurate. The Vitalograph AIM has an analog needle gauge that indicates the patient's inspiratory flow during the maneuver. The visual feedback received when keeping the analog needle gauge in the desired flow range helps the patient achieve the optimum flow. ${ }^{81}$ Skaer et $\mathrm{al}^{82}$ assessed the pMDI inhalation technique of 21 subjects using the Vitalograph AIM in a 6-week period. They reported that the device was a valuable training tool in patient education and led to significant improvement in physical function between baseline and follow-up.

In-Check DIAL. The In-Check DIAL (Clement Clarke International, Essex, United Kingdom) is a handheld inspiratory air-flow meter that measures peak inspiratory flow in patients of all ages by simulating the resistance of an inhaler, which helps to identify the most appropriate inhaler device for the patient. It is impressive in terms of determining appropriate first-time device prescription and checking patient technique by providing objective and realtime feedback to patients and health-care professionals. ${ }^{83,84}$ Amirav et al ${ }^{85}$ measured peak inspiratory flow with the In-Check DIAL in asthmatic children with and without DPI experience. A total of 223 children were studied, 123 of whom had no previous experience with DPIs. Measurement using the In-Check DIAL demonstrated that many children who had DPI experience could not generate the optimum peak inspiratory flows required with highresistance DPIs. ${ }^{85}$ Although the In-Check DIAL is designed for DPIs, it can measure peak inspiratory flow with no resistance to an inhalation. In this case, if patients' inspiratory flows are too high and they cannot slow down their inhalation rates through training with a pMDI, a DPI with some resistance can be chosen. ${ }^{86}$

Inhalation Manager. This is a computer-based measuring device that enables testing of the inhalation capacity of patients using DPIs. Therefore, the Inhalation Manager (Teva Pharmaceuticals, Amsterdam, The Netherlands) is a good device to identify the aerosol device that best suits the patient's needs and capabilities. It is also useful for teaching the optimum inhalation technique ${ }^{87}$ and allows prediction of mass output and particle size distribution. Steier et al ${ }^{88}$ conducted a prospective randomized crossover study in 200 subjects to teach correct handling and the optimum technique for the Autohaler and Turbuhaler. They evaluated the inhalation technique of subjects through a checklist (observational score), and the Inhalation Manager provided both an optical feedback and computer score. According to the findings of the study, the Inhalation Manager is a good device to improve inhalation technique with the Autohaler and Turbuhaler.

Mag-Flo Inhaler. The Mag-Flo inhaler (Fyne Dynamics, Essex, United Kingdom) is attached to a magnetic flow sensor that evaluates patients' ability to use a variety of DPIs such as the Turbohaler, Diskus, Accuhaler, HandiHaler (Boehringer Ingelheim Pharmaceuticals, Ridge- 


\section{Patient Education and Adherence to Aerosol Therapy}

field, Connecticut), and Novolizer (MEDA AB, Solna, Sweden). With the correct inhalation technique, the green light turns on, indicating that the patient's inhalation technique is correct. The Mag-Flo inhaler is helpful in teaching patients how to use DPIs with the correct inhalation technique and identifying patients who cannot use DPIs.

2Tone Trainer. The 2Tone Trainer (Canday Medical, Newmarket, United Kingdom) is similar to pMDIs in terms of its shape, but there is no medication inside the device. Patients who are prescribed a pMDI can practice with this device to mimic pMDI inhalation at the optimum flow for better aerosol deposition. A single audible tone indicates that the flow of the patient is optimum (30-60 $\mathrm{L} / \mathrm{min}$ ), whereas 2 tones indicate that the flow is $>60$ $\mathrm{L} / \mathrm{min}$. Al-Showair et al ${ }^{89}$ evaluated the effectiveness of the 2Tone Trainer in maintaining the correct inhalation technique with a pMDI after training and in improving clinical outcomes of asthma. A total of 108 subjects were studied in 3 groups: (1) good technique (GT), (2) verbal training (VT), and (3) 2Tone Trainer (2T). Subjects in the GT group had good coordination and slow inhalation rate, whereas subjects in the VT and $2 \mathrm{~T}$ groups had poor coordination and inhalation technique with pMDIs. All subjects in the VT and 2T groups received verbal training on the most desirable inhalation technique with pMDIs, but subjects in the $2 \mathrm{~T}$ group also learned how to use the 2Tone Trainer. Peak inspiratory flows and asthma quality-of-life questionnaire scores of the GT group did not change between visits, whereas both the VT and $2 \mathrm{~T}$ groups had a significant increase in asthma quality-of-life questionnaire scores. The overall changes in these parameters obtained in the $2 \mathrm{~T}$ group were significantly greater compared with VT group.

Turbutest. The Turbutest (Astra Draco, Lund, Sweden) is used to train patients on the correct use of the Turbuhaler or Flexhaler (AstraZeneca, Sodertalje, Sweden). It is connected to an electronic sensor that measures and visually indicates peak inspiratory flow: 3 lights indicate peak inspiratory flow of $>60 \mathrm{~L} / \mathrm{min} ; 2$ lights indicate peak inspiratory flow of $40-60 \mathrm{~L} / \mathrm{min}$; one light indicates peak inspiratory flow of $30-40 \mathrm{~L} / \mathrm{min}$; and no light indicates peak inspiratory flow of $<30 \mathrm{~L} / \mathrm{min}$. Two or 3 lights during inspiration with the Turbutest mean that the patient is able to generate sufficient peak inspiratory flow with DPIs such as the Turbuhaler and Flexhaler. Patients can also learn how to prime the Flexhaler using the Turbutest. Manuyakorn et al ${ }^{90}$ evaluated the sensitivity of the Turbutest in detecting the required peak inspiratory flow for using the Turbuhaler in 259 children with asthma in 3 age groups (5-6, 7-12, and 13-18 y of age). They reported that the sensitivity of the Turbutest was $94.4,98.8$, and $98.5 \%$, respectively. The Turbutest may be a valuable tool for evaluating and improving the inhalation technique of patients using the Turbuhaler.

\section{Monitoring Patient Adherence to Prescribed Aerosol Therapy}

Monitoring patient adherence to prescribed aerosol therapy is an ongoing process that needs to be done throughout disease management. Unfortunately, evaluation criteria for patient adherence have not been standardized with regard to good, adequate, or acceptable adherence to aerosol therapy. Because monitoring patient adherence has some impact on patient outcomes, clinicians should explore patient adherence in a nonthreatening and nonjudgmental manner. A number of methods are used to monitor patient adherence to aerosol therapy and can be classified as direct or indirect methods. Direct methods include direct observations of patients, such as canister weighing, pharmacy data, biochemical measures, and electronic monitoring. Indirect methods include patient self-reports, diaries, and clinicians' judgments (Table 5) ${ }^{91}$ It is important to note that these methods vary substantially in terms of accuracy and objectivity.

Patient Self-Reports or Diary Cards. Monitoring patient adherence with self-reports or diary cards is a fast, inexpensive, and frequently used technique. However, patients may over-report adherence when they use selfreports or diary cards ${ }^{92-96}$ due to memory bias and willingness to please physicians and health-care professionals. Patient self-reports have higher adherence rates compared with electronic device monitoring, canister weighing, and medication-dispensing records obtained from pharmacies. ${ }^{96}$ Therefore, clinician monitoring of patient adherence based on self-reports and diary cards is considered unreliable.

Clinical Judgment. This is the most commonly used but least reliable method for monitoring patient adherence to aerosol therapy. Although clinical judgment overestimates patient adherence to prescribed medications, it is still frequently used in clinical practice, as it is a fast and inexpensive method. Moreover, if the disease is under control, physicians sometimes forget to ask whether patients are continuing to take their medications. Using clinical judgment in addition to other methods such as pharmacy data or electronic monitoring can increase reliability.

Pharmacy Data. Obtaining registration of dispensed medication in pharmacies is an objective, inexpensive, and valid method to determine patient adherence. However, although data obtained from a pharmacy confirm that a prescription has been filled, only the dates of medication dispensing are provided. There is no guar- 
Table 5. Methods of Monitoring Adherence to Prescribed Aerosol Drug Therapy Based on Measures Noted in the Literature

\begin{tabular}{|c|c|c|c|}
\hline Method & Example & Strengths & Limitations \\
\hline Biochemical measures & $\begin{array}{l}\text { Analysis of blood, urine, or } \\
\text { secretions to measure drug level }\end{array}$ & Accurate, objective & $\begin{array}{l}\text { Expensive, intrusive, limited drug tests, } \\
\text { limited to recent drug therapy }\end{array}$ \\
\hline $\begin{array}{l}\text { Medication/device } \\
\text { monitors }\end{array}$ & $\begin{array}{l}\text { Electronic monitor records date and } \\
\text { time of inhaler use }\end{array}$ & Accurate, objective & $\begin{array}{l}\text { Cannot tell if patient actually received } \\
\text { dose, expensive, possible alteration of } \\
\text { patient habits }\end{array}$ \\
\hline $\begin{array}{l}\text { Observation of device } \\
\text { technique }\end{array}$ & $\begin{array}{l}\text { Direct review of patient performance } \\
\text { with aerosol device, usually } \\
\text { periodic }\end{array}$ & $\begin{array}{l}\text { Accurate with trained observer, } \\
\text { simple, objectively based }\end{array}$ & $\begin{array}{l}\text { Limited time of observation, limited to } \\
\text { device-use only (not dose schedule), } \\
\text { requires staff time }\end{array}$ \\
\hline Medical/pharmacy records & $\begin{array}{l}\text { Retrospective review of patient } \\
\text { records or refills }\end{array}$ & $\begin{array}{l}\text { Objective, relatively simple to } \\
\text { obtain }\end{array}$ & $\begin{array}{l}\text { Time required to obtain patient data, } \\
\text { limited to detecting non-refills, no } \\
\text { information on correct patient use or } \\
\text { scheduling of drug refills }\end{array}$ \\
\hline $\begin{array}{l}\text { Monitoring remaining dose } \\
\text { counts of medication }\end{array}$ & $\begin{array}{l}\text { pMDI canister weighing, DPI doses } \\
\text { left, SVN doses or solution } \\
\text { packages left }\end{array}$ & Simple, objective, low cost & $\begin{array}{l}\text { Possible patient deceit by wasting doses, } \\
\text { no information on actual dosing } \\
\text { schedule, requires staff time }\end{array}$ \\
\hline $\begin{array}{l}\text { Clinical judgment of } \\
\text { provider }\end{array}$ & $\begin{array}{l}\text { Global judgment of health-care } \\
\text { provider during clinic visits }\end{array}$ & Quick, low cost & Low validity and reliability \\
\hline Patient self-report & $\begin{array}{l}\text { Periodic recall survey or interview, } \\
\text { patient diary }\end{array}$ & $\begin{array}{l}\text { Fast for health-care providers, } \\
\text { ease of use, low cost }\end{array}$ & Vulnerable to patient error or deceit \\
\hline \multicolumn{4}{|c|}{$\begin{array}{l}\text { From Reference } 35 \text {, with permission. } \\
\text { pMDI = pressurized metered-dose inhaler } \\
\text { DPI = dry powder inhalers } \\
\text { SVN = small-volume nebulizer }\end{array}$} \\
\hline
\end{tabular}

antee that the patients take the medication as prescribed by their doctors or that correct technique is used with the device during the administration of medication. In addition, if a patient obtains medication from more than one pharmacy, pharmacy data are less reliable. Therefore, patients should be instructed to get their medications from a single pharmacy to eliminate these types of issues and increase reliability of data on patient adherence. ${ }^{97,98}$ Sherman et al ${ }^{99}$ evaluated the adherence rates of 116 children by obtaining their medication-dispensing records from 55 pharmacies and reported a mean adherence rate of $61 \%$. They also confirmed that the accuracy of pharmacy records was $92 \%$ by cost-reimbursement records of insurance companies.

Biologic Measures. Biologic measures have the advantage of confirming the presence of the medication in blood, urine, or saliva. They can be used for a limited number of oral medications, but it is hard to detect the presence of inhaled drugs. The need for repeated analysis and high costs are also disadvantages of biologic measures.

Electronic Device Monitoring. The most well-known electronic device monitors are the Chronolog DOSER (Meditrack Products, Hudson, Massachusetts), and Smartinhaler (Nexus6, Dayton, Ohio) (Fig. 2). They are connected to the inhaler and record the date and time of medication administration. Some of these devices have an alarm mechanism that informs patients about the number of doses remaining in the inhaler. Electronic device monitoring is expensive, but it provides accurate data on patient use of medications. ${ }^{2,100-103}$ Although there are many inhalers available for the treatment of pulmonary diseases, electronic device monitors that evaluate patient adherence with all the inhaled medications have not yet been developed. Clinical research that investigates the accuracy, feasibility, and clinical outcomes of electronic monitors in patient adherence is warranted.

\section{Promoting Patient Adherence to Aerosol Therapy}

Promoting patient adherence to aerosol therapy is an important concept in aerosol medicine. Table 6 shows suggested actions to improve patient adherence to aerosol therapy. Although there is a general agreement in previous research regarding inadequate patient education and adherence to prescribed inhaled medications, the required resources of time and organization in preparing an effective education program for patients is still missing. Relatively few initiatives exist in clinical practice to correct the problem with nonadherence to aerosol therapy. Due to lack of incentives and busy work schedules of physicians and health-care professionals, patients show poor understanding of prescribed therapy and fail to use aerosol devices correctly. Therefore, physicians and health-care professionals should go the extra mile in promoting patient adherence to prescribed inhaled medications. Despite lack of incentives 

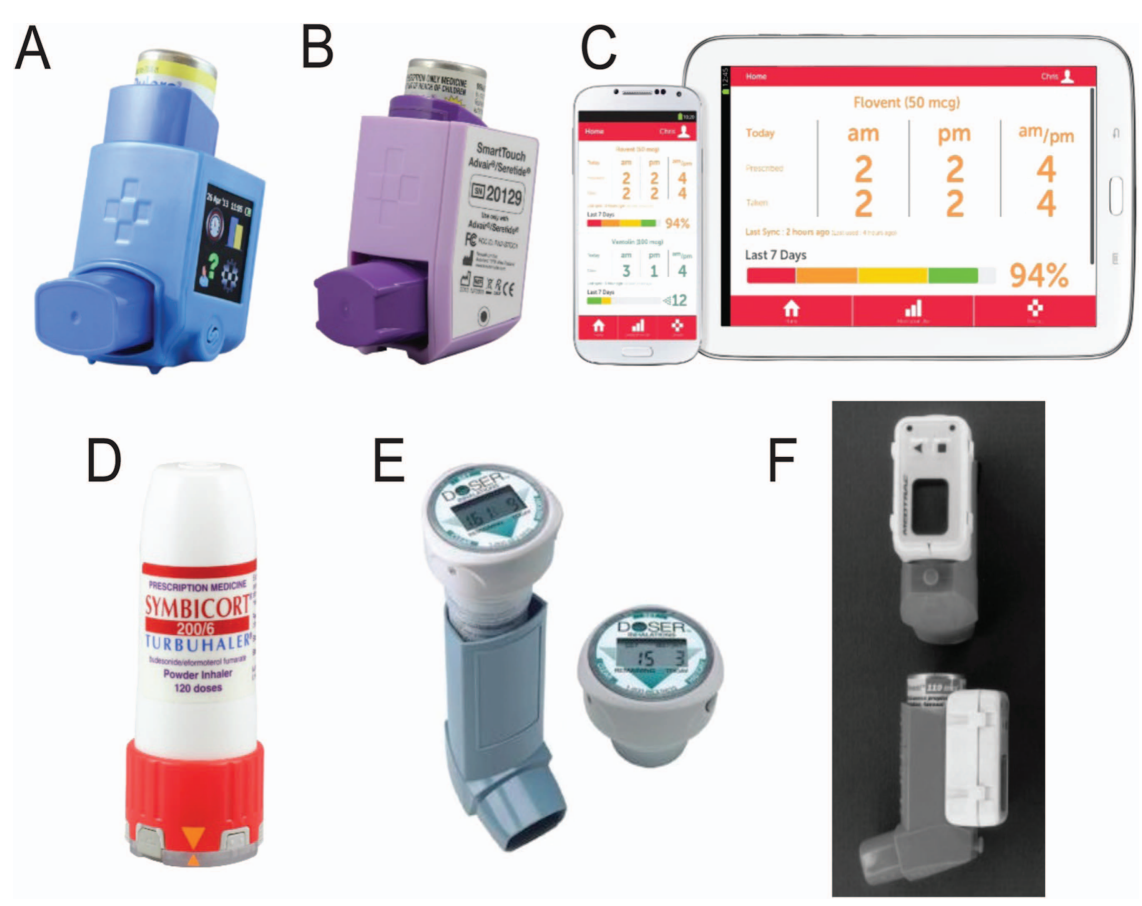

Fig. 2. Commercially available electronic device monitors in aerosol medicine. A: Dulera, courtesy Smartinhaler. B: Advair/Seretide, courtesy Smartinhaler. C: Nexus6 app, courtesy Smartinhaler. D: Symbicort, courtesy Smartinhaler, E: DOSER, courtesy PuffMinder.com. F: MDILog, courtesy Westmed.

and time for patient education, health-care professionals can use patient admission to the hospital as a key opportunity to teach and promote adherence to aerosol therapy. They can work closely with patients at the bedside to assist with their treatments and act as a mentor to improve patient education on aerosol therapy.

Promoting better adherence to prescribed medications includes several important strategies: (1) understanding health-related behavior, (2) preparing patients and their caregivers, (3) promoting the patient-physician relationship, (4) promoting the role of respiratory therapists and other health-care professionals in patient education and adherence, (5) establishing patient-centered teamwork in aerosol medicine, and (6) working with policymakers to resolve problems with patient education and adherence. These strategies are explained in detail below.

Understanding Health-Related Behavior. Patients have certain beliefs about their health, treatments, and capacity to perform certain techniques with aerosol devices. Once patient beliefs and concerns about aerosol therapy, prescribed medications, and adverse effects are well understood, health-care professionals can determine the reasons for nonadherence to therapy and provide necessary explanations to patients. Through good communication and listening skills, they can correct patient concerns and other issues that reduce therapy adherence.
Preparing Patients and Their Caregivers. Empowering the patient to be a full partner in the process of care is essential to achieve patient adherence to aerosol therapy. If patients understand that their own actions impact their health, they will be more willing to take prescribed inhaled medications and maintain aerosol therapy, which will lead to improved clinical outcomes. ${ }^{104}$ Some patients do not take their inhaled medications when they feel well regardless of the actual extent of their illness. Others are not willing to use medications when they see no perceived benefit associated with them. Through effective educational interventions, patients and their caregivers can understand the disease and the importance of taking medications as prescribed. In patient education sessions, clinicians should emphasize how the new knowledge of prescribed medication and aerosol devices will be valuable and relevant to them. Once patients gain a comprehensive understanding of their disease, medications, and treatments, they will be goal-oriented and self-directed in maintaining the requirements of aerosol therapy. They will become a full partner in the process of care instead of passive participants with their own treatments. ${ }^{104}$ It is also important to include patients' families and caregivers in this process. Previous research showed that communicating with caregivers and obtaining family support reduced barriers about subjects' attitude toward medication and improved asthma control and quality of life. ${ }^{105-107}$ 
Table 6. Suggested Actions to Improve Patient Adherence to Aerosol Therapy

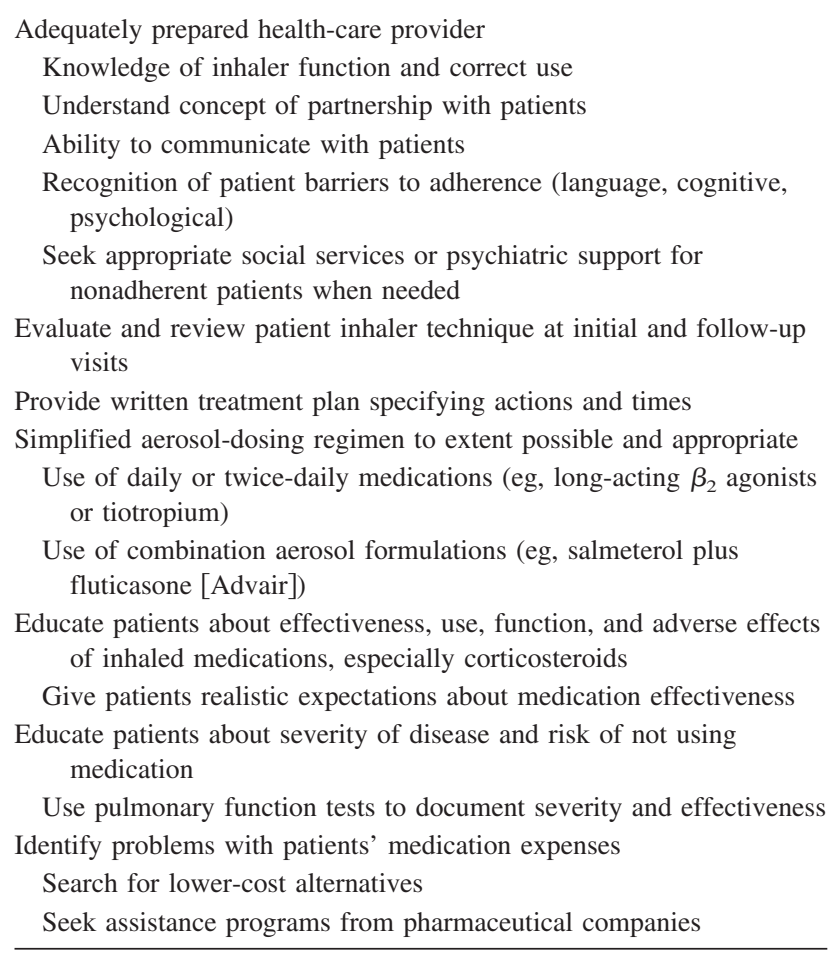

Promoting the Patient-Physician Relationship. The patient-physician relationship is very important in patient adherence to prescribed medications. When patients have a low level of satisfaction and faith in their physician, they show poor adherence. ${ }^{108,109}$ Therefore, the quality of communication between patient and physician may have a major influence not only on patient adherence, but also on health outcomes. Through good communication, verbal praise, and encouragement, physicians can provide more information to their patients while encouraging them to ask more questions and express their concerns about inhaled medications to identify and correct root causes of nonadherence. ${ }^{110}$ Physicians can also use nonverbal behaviors such as leaning forward or sitting next to the patient to indicate attention and promote their relationship with their patients. ${ }^{111}$ Physicians should correct the problems underlying nonadherence before changing the medication or increasing the dose in clinical practice.

\section{Promoting the Role of Respiratory Therapists and Other Health-Care Professionals in Patient Educa-}

tion. Effective aerosol therapy in the treatment of pulmonary diseases can be accomplished through the preparation of respiratory therapists and other health-care professionals who will be responsible for patient education on aerosol therapy and self-management in the disease process. Once respiratory therapists and health-care professionals have a complete understanding of health-related behaviors, they can prepare patients for therapy by empowering them to be full partners in the process of care. They can then use general principles of education to teach psychomotor skills and use effective teaching strategies to improve adherence. It is also important to train respiratory therapists and other health-care professionals so that they can demonstrate proper use and maintenance of aerosol devices to assist patients in improving the effectiveness of aerosol therapy.

Establishing Patient-Centered Teamwork in Aerosol Medicine. Delivery of aerosolized medications to patients is a complex procedure that requires patient-centered teamwork among physicians, health-care professionals, patients, and caregivers, as well as pharmaceutical companies and policymakers. To accomplish this goal, each institution should develop an interdisciplinary patient-centered teamwork system to promote communication, mutual understanding, partnership, and shared decision making. The scope of practice within each institution should be beyond patient education and provide patients with the value and practice of a lifelong healthy lifestyle with use of inhaled medications. Pharmaceutical companies should also promote patient education by regularly providing health-care institutions with placebo inhalers.

\section{Working With Policymakers to Resolve Problems} With Patient Education and Adherence. Due to nonadherence to inhaled medications and poor clinical outcomes, health-care cost, mortality, and morbidity in patients with pulmonary diseases are high and must be addressed by appropriate policy change. There is a need for policy development instituting patient education programs in all health-care settings that will address patient assessment on correct inhalation technique and training and patient adherence to prescribed medications. Also, clinicians should choose an aerosol device with the lowest out-of-pocket expense for the patient. ${ }^{74}$ Although costs of aerosol device/drug combinations vary widely, the medical insurance status will determine the cost to the patient. If patients cannot afford the drug, they will not adhere to aerosol therapy despite the fact that they understand the importance of taking medications for disease management. Therefore, policymakers should utilize strategic and innovative approaches to promote insurance coverage for prescribed inhaled medication and patient education sessions prepared by health-care professionals. Otherwise, problems with patient education and adherence in aerosol medicine cannot be overcome, and future increases in cost expenditure due to unscheduled health-care utilization will continue to be an issue for inhaled medications. 


\section{Patient Education and Adherence to Aerosol Therapy}

\section{Summary}

Nonadherence to prescribed medications results in poor clinical control and increases unscheduled health-care utilization, morbidity, and mortality. Health-care professionals still lack the necessary knowledge on how to use aerosol devices and cannot teach patients the correct technique. Clinicians should work with patients, families, and caregivers to identify barriers to adherence and determine strategies to overcome issues with poor adherence to aerosol therapy. Although the best educational intervention is one that is individualized, other effective educational interventions include: using the device preferred by the patient, keeping the device consistent, following up with patients and checking inhaler technique, using written and verbal instructions along with hands-on demonstration, providing repetitive instruction, highlighting incorrect steps on the inhaler technique label, and using training devices. Although poor adherence to prescribed medications is difficult to identify, methods that are used to monitor adherence include patient diaries and self-reports, biochemical measures, medical pharmacy records, clinical judgment through direct observation of patients, and electronic device monitoring. There is no single solution that will solve all issues associated with nonadherence to aerosol therapy. However, promoting patient adherence to aerosol therapy may be achieved by understanding health-related patient behavior, preparing patients and caregivers, promoting the patient-physician relationship, increasing the skills of health-care professionals in patient education, establishing patient-centered teamwork, and working with policymakers to resolve problems with patient education and adherence.

\section{REFERENCES}

1. Everard ML. Role of inhaler competence and contrivance in "difficult asthma". Paediatr Respir Rev 2003;4(2):135-142.

2. Lareau SC, Yawn BP. Improving adherence with inhaler therapy in COPD. Int J Chron Obstruct Pulmon Dis 2010;5:401-406.

3. Brennan VK, Osman LM, Graham H, Critchlow A, Everard ML. True device compliance: the need to consider both competence and contrivance. Respir Med 2005;99(1):97-102.

4. Everard ML. CFC transition: the emperor's new clothes. Each class of drug deserves a delivery system that meets its own requirements. Thorax 2000;55(10):811-814.

5. Melani AS, Bonavia M, Cilenti V, Cinti C, Lodi M, Martucci P, et al. Inhaler mishandling remains common in real life and is associated with reduced disease control. Respir Med 2011;105(6): 930-938

6. Vestbo J, Anderson JA, Calverley PM, Celli B, Ferguson GT, Jenkins $\mathrm{C}$, et al. Adherence to inhaled therapy, mortality and hospital admission in COPD. Thorax 2009;64(11):939-943.

7. Birkhead G, Attaway NJ, Strunk RC, Townsend MC, Teutsch S. Investigation of a cluster of deaths of adolescents from asthma: evidence implicating inadequate treatment and poor patient adherence with medications. J Allergy Clin Immunol 1989;84(4 Pt 1): $484-491$
8. Williams LK, Pladevall M, Xi H, Peterson EL, Joseph C, Lafata JE, et al. Relationship between adherence to inhaled corticosteroids and poor outcomes among adults with asthma. J Allergy Clin Immunol 2004;114(6):1288-1293.

9. Milgrom H, Bender B, Ackerson L, Bowry P, Smith B, Rand C. Noncompliance and treatment failure in children with asthma. J Allergy Clin Immunol 1996;98(6 Pt 1):1051-1057.

10. Levy ML, Hardwell A, McKnight E, Holmes J. Asthma patients' inability to use a pressurised metered-dose inhaler (pMDI) correctly correlates with poor asthma control as defined by the global initiative for asthma (GINA) strategy: a retrospective analysis. Prim Care Respir J 2013;22(4):406-411.

11. Fink JB, Rubin BK. Problems with inhaler use: a call for improved clinician and patient education. Respir Care 2005;50(10):1360-1374; discussion 1374-1375.

12. DiMatteo MR. Variations in patients' adherence to medical recommendations: a quantitative review of 50 years of research. Med Care 2004;42(3):200-209.

13. Bender BG, Pedan A, Varasteh LT. Adherence and persistence with fluticasone propionate/salmeterol combination therapy. J Allergy Clin Immunol 2006;118(4):899-904.

14. Haupt D, Krigsman K, Nilsson JL. Medication persistence among patients with asthma/COPD drugs. Pharm World Sci 2008;30(5): 509-514.

15. Krigsman K, Moen J, Nilsson JL, Ring L. Refill adherence by the elderly for asthma/chronic obstructive pulmonary disease drugs dispensed over a 10-year period. J Clin Pharm Ther 2007;32(6):603611.

16. Krigsman K, Nilsson JL, Ring L. Adherence to multiple drug therapies: refill adherence to concomitant use of diabetes and asthma/ COPD medication. Pharmacoepidemiol Drug Saf 2007;16(10):11201128.

17. Krigsman K, Nilsson JL, Ring L. Refill adherence for patients with asthma and COPD: comparison of a pharmacy record database with manually collected repeat prescriptions. Pharmacoepidemiol Drug Saf 2007;16(4):441-448.

18. World Health Organization. Adherence to long term therapies: evidence for action. 2003. http://www.who.int/chp/knowledge/ publications/adherence_full_report.pdf. Accessed October 23, 2014.

19. Milgrom H, Wamboldt F, Bender B. Monitoring adherence to the therapy of asthma. Curr Opin Allergy Clin Immunol 2002;2(3): 201-205.

20. Restrepo RD, Alvarez MT, Wittnebel LD, Sorenson H, Wettstein $\mathrm{R}$, Vines DL, et al. Medication adherence issues in patients treated for COPD. Int J Chron Obstruct Pulmon Dis 2008;3(3):371-384.

21. Claxton AJ, Cramer J, Pierce C. A systematic review of the associations between dose regimens and medication compliance. Clin Ther 2001;23(8):1296-1310.

22. Jung E, Pickard AS, Salmon JW, Bartle B, Lee TA. Medication adherence and persistence in the last year of life in COPD patients. Respir Med 2009;103(4):525-534.

23. Jónasson G, Carlsen KH, Mowinckel P. Asthma drug adherence in a long term clinical trial. Arch Dis Child 2000;83(4):330-333.

24. Hardwell A, Barber V, Hargadon T, McKnight E, Holmes J, Levy ML. Technique training does not improve the ability of most patients to use pressurised metered-dose inhalers (pMDIs). Prim Care Respir J 2011;20(1):92-96.

25. Lavorini F, Magnan A, Dubus JC, Voshaar T, Corbetta L, Broeders $\mathrm{M}$, et al. Effect of incorrect use of dry powder inhalers on management of patients with asthma and COPD. Respir Med 2008; 102(4):593-604

26. Brocklebank D, Ram F, Wright J, Barry P, Cates C, Davies L, et al. Comparison of the effectiveness of inhaler devices in asthma and 
chronic obstructive airways disease: a systematic review of the literature. Health Technol Assess 2001;5(26):1-149.

27. Lenney J, Innes JA, Crompton GK. Inappropriate inhaler use: assessment of use and patient preference of seven inhalation devices. EDICI. Respir Med 2000;94(5):496-500.

28. Kim SH, Kwak HJ, Kim TB, Chang YS, Jeong JW, Kim CW, et al. Inappropriate techniques used by internal medicine residents with three kinds of inhalers (a metered dose inhaler, Diskus, and Turbuhaler): changes after a single teaching session. J Asthma 2009; 46(9):944-950.

29. Cunha AJ, Santos MA, Galvão MG, Ibiapina AA. Knowledge of pediatricians in Rio de Janeiro, Brazil, about inhalation therapy in asthmatic children. Allergol Immunopathol 2003;31(2):87-90.

30. Self TH, Arnold LB, Czosnowski LM, Swanson JM, Swanson H. Inadequate skill of healthcare professionals in using asthma inhalation devices. J Asthma 2007;44(8):593-598.

31. Amirav I, Burg F. The need to educate health professionals about childhood asthma. Arch Pediatr Adolesc Med 1994;148(12):13391343.

32. Benjaponpitak S, Kraisarin C, Direkwattanachai C, Sasisakunporn C. Incorrect use of metered dose inhaler by pediatric residents. J Med Assoc Thai 1996;79(2):122-126.

33. Rau JL. Determinants of patient adherence to an aerosol regimen. Respir Care 2005;50(10):1346-1356; discussion 1357-1359.

34. Crompton GK. Problems patients have using pressurized aerosol inhalers. Eur J Respir Dis Suppl 1982;119:101-104.

35. Gayrard P, Orehek J. [Inadequate use of pressurized aerosols by asthmatic patients [author's transl]. Respiration 1980;40(1):47-52. Article in French.

36. Plaza V, Sanchis J. Medical personnel and patient skill in the use of metered dose inhalers: a multicentric study. CESEA Group. Respiration 1998;65(3):195-198.

37. van Beerendonk I, Mesters I, Mudde AN, Tan TD. Assessment of the inhalation technique in outpatients with asthma or chronic obstructive pulmonary disease using a metered-dose inhaler or dry powder device. J Asthma 1998;35(3):273-279.

38. Larsen JS, Hahn M, Ekholm B, Wick KA. Evaluation of conventional press-and-breathe metered-dose inhaler technique in 501 patients. J Asthma 1994;31(3):193-199.

39. Fink J, Hodder R. Adherence and inhaler devices in COPD. Respir Ther $2011 ; 6: 28-33$.

40. Rubin BK, Fink JB. Optimizing aerosol delivery by pressurized metered-dose inhalers. Respir Care 2005;50(9):1191-1200.

41. Rubin BK, Durotoye L. How do patients determine that their metered-dose inhaler is empty? Chest 2004;126(4):1134-1137.

42. Eisen SA, Miller DK, Woodward RS, Spitznagel E, Przybeck TR. The effect of prescribed daily dose frequency on patient medication compliance. Arch Intern Med 1990;150(9):1881-1884.

43. Cramer JA, Mattson RH, Prevey ML, Scheyer RD, Ouellette VL. How often is medication taken as prescribed? A novel assessment technique. JAMA 1989;261(22):3273-3277.

44. Coutts JA, Gibson NA, Paton JY. Measuring compliance with inhaled medication in asthma. Arch Dis Child 1992;67(3):332-333.

45. Bender BG. Overcoming barriers to nonadherence in asthma treatment. J Allergy Clin Immunol 2002;109(6 Suppl):S554-S559.

46. Stoloff SW, Stempel DA, Meyer J, Stanford RH, Carranza Rosenzweig JR. Improved refill persistence with fluticasone propionate and salmeterol in a single inhaler compared with other controller therapies. J Allergy Clin Immunol 2004;113(2):245-251.

47. Sovani MP, Whale CI, Oborne J, Cooper S, Mortimer K, Ekström $\mathrm{T}$, et al. Poor adherence with inhaled corticosteroids for asthma: can using a single inhaler containing budesonide and formoterol help? Br J Gen Pract 2008;58(546):37-43.
48. Bender B, Milgrom H, Rand C, Ackerson L. Psychological factors associated with medication nonadherence in asthmatic children. J Asthma 1998;35(4):347-353.

49. Bender B, Milgrom H, Apter A. Adherence intervention research: what have we learned and what do we do next? J Allergy Clin Immunol 2003;112(3):489-494.

50. Graves MM, Adams CD, Bender JA, Simon S, Portnoy AJ. Volitional nonadherence in pediatric asthma: parental report of motivating factors. Curr Allergy Asthma Rep 2007;7(6):427-432.

51. Menckeberg TT, Bouvy ML, Bracke M, Hugtenburg JG, Lammers JW, Raaijmakers JA. Patients' understanding of the reasons for starting and discontinuing inhaled corticosteroids. Br J Clin Pharmacol 2008;66(2):255-260.

52. DiMatteo MR, Haskard KB, Williams SL. Health beliefs, disease severity, and patient adherence: a meta-analysis. Med Care 2007; 45(6):521-528.

53. Bender BG, Long A, Parasuraman B, Tran ZV. Factors influencing patient decisions about the use of asthma controller medication. Ann Allergy Asthma Immunol 2007;98(4):322-328.

54. DiMatteo MR. Enhancing patient adherence to medical recommendations. JAMA 1994;271(1):79-83.

55. Serra-Batlles J, Plaza V, Badiola C, Morejón E, Inhalation Devices Study Group. Patient perception and acceptability of multidose dry powder inhalers: a randomized crossover comparison of Diskus/ Accuhaler with Turbuhaler. J Aerosol Med 2002;15(1):59-64.

56. Dowson CA, Town GI, Frampton C, Mulder RT. Psychopathology and illness beliefs influence COPD self-management. J Psychosom Res 2004;56(3):333-340.

57. Fan VS, Giardino ND, Blough DK, Kaplan RM, Ramsey SD. Costs of pulmonary rehabilitation and predictors of adherence in the National Emphysema Treatment Trial. COPD 2008;5(2):105-116.

58. Strunk RC, Bender B, Young DA, Sagel S, Glynn E, Caesar M, Lawhon C. Predictors of protocol adherence in a pediatric asthma clinical trial. J Allergy Clin Immunol 2002;110(4):596-602.

59. Vasbinder E, Dahhan N, Wolf B, Zoer J, Blankman E, Bosman D, et al. The association of ethnicity with electronically measured adherence to inhaled corticosteroids in children. Eur J Clin Pharmacol 2013;69(3):683-690.

60. Mosnaim G, Li H, Martin M, Richardson D, Belice PJ, Avery E, et al. Factors associated with levels of adherence to inhaled corticosteroids in minority adolescents with asthma. Ann Allergy Asthma Immunol 2014;112(2):116-120.

61. Le TT, Bilderback A, Bender B, Wamboldt FS, Turner CF, Rand CS, Bartlett SJ. Do asthma medication beliefs mediate the relationship between minority status and adherence to therapy? J Asthma 2008;45(1):33-37.

62. Rubin BK. What does it mean when a patient says, "my asthma medication is not working?". Chest 2004;126(3):972-981.

63. Rubin BK. Adherence to asthma therapy: the "blocked receptor". Pediatr Pulmonol Suppl 2004;26:36-37.

64. Ari A, Restrepo RD. Aerosol delivery device selection for spontaneously breathing patients: 2012. Respir Care 2012;57(4):613-626.

65. Self TH, Wallace JL, George CM, Howard-Thompson A, Schrock SD. Inhalation therapy: help patients avoid these mistakes. J Fam Pract 2011;60(12):714-721.

66. Guevara JP, Wolf FM, Grum CM, Clark NM. Effects of educational interventions for self management of asthma in children and adolescents: systematic review and meta-analysis. BMJ 2003; 326(7402):1308-1309.

67. Eakin MN, Rand CS. Improving patient adherence with asthma self-management practices: what works? Ann Allergy Asthma Immunol 2012;109(2):90-92.

68. Janson SL, McGrath KW, Covington JK, Cheng SC, Boushey HA Individualized asthma self-management improves medication ad- 


\section{Patient Education and Adherence to Aerosol Therapy}

herence and markers of asthma control. J Allergy Clin Immunol 2009;123(4):840-846.

69. Anderson P. Patient preference for and satisfaction with inhaler devices. Eur Respir Rev 2005;14(96):109-116.

70. Schulte M, Osseiran K, Betz R, Wencker M, Brand P, Meyer T, Haidl P. Handling of and preferences for available dry powder inhaler systems by patients with asthma and COPD. J Aerosol Med Pulm Drug Deliv 2008;21(4):321-328.

71. Molimard M, Colthorpe P. Inhaler devices for chronic obstructive pulmonary disease: insights from patients and healthcare practitioners. J Aerosol Med Pulm Drug Deliv. 2014. [Epub ahead of print] doi: 10.1089/jamp.2014.1142.

72. van der Palen J, Klein JJ, van Herwaarden CL, Zielhuis GA, Seydel ER. Multiple inhalers confuse asthma patients. Eur Respir J 1999; 14(5):1034-1037.

73. Dolovich MB, Ahrens RC, Hess DR, Anderson P, Dhand R, Rau JL, et al. Device selection and outcomes of aerosol therapy: evidence-based guidelines: American College of Chest Physicians/ American College of Asthma, Allergy, and Immunology. Chest 2005;127(1):335-371.

74. Ari A, Fink J. Guidelines to aerosol devices in infants, children and adults: which to choose, why and how to achieve effective aerosol therapy? Expert Rev Respir Med 2011;5(4):561-572.

75. Hess DR. Aerosol delivery devices in the treatment of asthma. Respir Care 2008;53(6):699-723; discussion 723-725.

76. Safeer RS, Keenan J. Health literacy: the gap between physicians and patients. Am Fam Physician 2005;72(3):463-468.

77. Goodyer L, Savage I, Dikmen Z. Inhaler technique in Turkish people with poor English: a case of information discrimination? Pharm World Sci 2006;28(2):107-114.

78. Takemura M, Mitsui K, Itotani R, Ishitoko M, Suzuki S, Matsumoto M, et al. Relationships between repeated instruction on inhalation therapy, medication adherence, and health status in chronic obstructive pulmonary disease. Int J Chron Obstruct Pulmon Dis 2011;6:97-104.

79. Basheti IA, Armour CL, Bosnic-Anticevich SZ, Reddel HK. Evaluation of a novel educational strategy, including inhaler-based reminder labels, to improve asthma inhaler technique. Patient Educ Couns 2008;72(1):26-33.

80. Hardy KJ, O'Brien SV, Furlong NJ. Information given to patients before appointments and its effect on non-attendance rate. BMJ 2001;323(7324):1298-1300.

81. Lavorini F, Levy ML, Corrigan C, Crompton G. The ADMIT series-issues in inhalation therapy. 6) Training tools for inhalation devices. Prim Care Respir J 2010;19(4):335-341.

82. Skaer TL, Wilson CB, Sclar DA, Arnold TA, Garcia CF, Schmidt $\mathrm{LN}$, et al. Metered-dose inhaler technique and quality of life with airways disease: assessing the value of the Vitalograph in educational intervention. J Int Med Res 1996;24(4):369-375.

83. van der Palen J. Peak inspiratory flow through Diskus and Turbuhaler, measured by means of a peak inspiratory flow meter (InCheck DIAL). Respir Med 2003;97(3):285-289.

84. Azouz W, Chrystyn H. Clarifying the dilemmas about inhalation techniques for dry powder inhalers: integrating science with clinical practice. Prim Care Respir J 2012;21(2):208-213.

85. Amirav I, Newhouse MT, Mansour Y. Measurement of peak inspiratory flow with in-check dial device to simulate low-resistance (Diskus) and high-resistance (Turbohaler) dry powder inhalers in children with asthma. Pediatr Pulmonol 2005;39(5):447-451.

86. Chrystyn $\mathrm{H}$. Is inhalation rate important for a dry powder inhaler? Using the In-Check Dial to identify these rates. Respir Med 2003; 97(2):181-187.

87. Kamin WE, Genz T, Roeder S, Scheuch G, Cloes R, Juenemann R, Trammer $\mathrm{T}$. The inhalation manager: a new computer-based device to assess inhalation technique and drug delivery to the patient. J Aerosol Med 2003;16(1):21-29.

88. Steier J, Trammer T, Cloes RM, Petro W. Optical feedback training of inhalation with Autohaler and Turbuhaler in COPD patients. Lung 2003;181(4):183-192.

89. Al-Showair RA, Pearson SB, Chrystyn H. The potential of a 2Tone Trainer to help patients use their metered-dose inhalers. Chest 2007; 131(6):1776-1782.

90. Manuyakorn W, Direkwattanachai C, Benjaponpitak S, Kamchaisatian W, Sasisakulporn C, Teawsomboonkit W. Sensitivity of Turbutester and Accuhaler tester in asthmatic children and adolescents. Pediatr Int 2010;52(1):118-125.

91. Rand CS, Wise RA. Measuring adherence to asthma medication regimens. Am J Respir Crit Care Med 1994;149(2 Pt 2):S69-S76; discussion S77-S78.

92. Williams LK, Joseph CL, Peterson EL, Wells K, Wang M, Chowdhry VK, et al. Patients with asthma who do not fill their inhaled corticosteroids: a study of primary nonadherence. J Allergy Clin Immunol 2007;120(5):1153-1159.

93. Winkelstein ML, Huss K, Butz A, Eggleston P, Vargas P, Rand C. Factors associated with medication self-administration in children with asthma. Clin Pediatr 2000;39(6):337-345.

94. Burkhart PV, Dunbar-Jacob JM, Rohay JM. Accuracy of children's self-reported adherence to treatment. J Nurs Scholarsh 2001;33(1): 27-32.

95. McDonald HP, Garg AX, Haynes RB. Interventions to enhance patient adherence to medication prescriptions: scientific review. JAMA 2002;288(22):2868-2879.

96. Bender B, Wamboldt FS, O'Connor SL, Rand C, Szefler S, Milgrom H, Wamboldt MZ. Measurement of children's asthma medication adherence by self report, mother report, canister weight, and Doser CT. Ann Allergy Asthma Immunol 2000;85(5):416421.

97. McQuaid EL, Kopel SJ, Klein RB, Fritz GK. Medication adherence in pediatric asthma: reasoning, responsibility, and behavior. J Pediatr Psychol 2003;28(5):323-333.

98. Kelloway JS, Wyatt R, DeMarco J, Adlis S. Effect of salmeterol on patients' adherence to their prescribed refills for inhaled corticosteroids. Ann Allergy Asthma Immunol 2000;84(3):324-328.

99. Sherman J, Hutson A, Baumstein S, Hendeles L. Telephoning the patient's pharmacy to assess adherence with asthma medications by measuring refill rate for prescriptions. J Pediatr 2000;136(4):532536.

100. Jentzsch NS, Camargos PA. Methods of assessing adherence to inhaled corticosteroid therapy in children and adolescents: adherence rates and their implications for clinical practice. J Bras Pneumol 2008;34(8):614-621.

101. Denyer J. Adherence monitoring in drug delivery. Expert Opin Drug Deliv 2010;7(10):1127-1131.

102. Foster JM, Smith L, Usherwood T, Sawyer SM, Rand CS, Reddel HK. The reliability and patient acceptability of the SmartTrack device: a new electronic monitor and reminder device for metered dose inhalers. J Asthma 2012;49(6):657-662.

103. Julius SM, Sherman JM, Hendeles L. Accuracy of three electronic monitors for metered-dose inhalers. Chest 2002;121(3):871876.

104. Lewis RM, Fink JB. Promoting adherence to inhaled therapy: building partnerships through patient education. Respir Care Clin N Am 2001;7(2):277-301.

105. Rhee H, Belyea MJ, Brasch J. Family support and asthma outcomes in adolescents: barriers to adherence as a mediator. J Adolesc Health 2010;47(5):472-478.

106. Bruzzese JM, Idalski Carcone A, Lam P, Ellis DA, Naar-King S. Adherence to asthma medication regimens in urban African Amer- 


\section{Patient Education and Adherence to Aerosol Therapy}

ican adolescents: application of self-determination theory. Health Psychol 2014;33(5):461-464.

107. Sleath B, Carpenter DM, Slota C, Williams D, Tudor G, Yeatts K, et al. Communication during pediatric asthma visits and self-reported asthma medication adherence. Pediatrics 2012;130(4):627-633.

108. George J, Kong DC, Thoman R, Stewart K. Factors associated with medication nonadherence in patients with COPD. Chest 2005; 128(5):3198-3204
109. Tarn DM, Heritage J, Paterniti DA, Hays RD, Kravitz RL, Wenger NS. Physician communication when prescribing new medications. Arch Intern Med 2006;166(17):1855-1862.

110. Hernandez DV, Schmaling KB. Understanding and resolving adherence problems. Clin Rev Allergy Immunol 2004;27(2):6573 .

111. Chapman KR, Walker L, Cluley S, Fabbri L. Improving patient compliance with asthma therapy. Respir Med 2000;94(1):2-9.

\section{Discussion}

Berlinski: The issue of a single platform, something I alluded to yesterday, is only going to get better if the regulatory agencies provide some sort of incentive to manufacturers of inhaled corticosteroids/combination therapy to have the short-acting bronchodilator also available. In asthma, I think that the most common thing you use is your DPI for the controller, but the reliever is an MDI. Unless there is some sort of incentive from regulatory agencies, that's going to remain a problem. I want to echo your words about the role of the respiratory therapist (RT) in patient education. I can proudly say that at my institution at each visit, my patients with asthma, cystic fibrosis (CF), or other conditions are being assessed by RTs who review their inhaler technique and provide education. Unfortunately, there are not many places (which I know from talking to some of my colleagues) where the value that this brings to the patients is recognized.

Ari: Excellent point! Thanks so much for bringing up the topic of regulatory agencies. I also believe that working with regulatory agencies and policymakers is essential in resolving problems with patient education and adherence. Unless there is a new policy addressing the issues with patient education and adherence to prescribed inhaled medications, patients with pulmonary diseases will continue to have disease instability, poor clinical outcomes, and increased school/work absenteeism, emergency room visits, and hospital admissions. We also need physicians like you who understand the role and importance of RTs in patient education and adherence to prescribed inhaled medications.

Hill: This is an incredibly difficult problem, and you've shown a lot of data that are consistent with everybody's experience, which is that adherence with very expensive medicines is abhorrent. There are so many barriers that we have put in the way here, and although you've made some great recommendations as to how to deal with it, it's really hard to implement a lot of them. Among the many problems is that we now have a whole proliferation of different kinds of devices, and it's very hard for anybody to be entirely familiar with all of them. We've had a bunch of new inhalers come out recently. Another thing that's happening is that many hospitals, including my own, no longer allow drug samples. We don't allow samples because the regulations have made it impossible to hand them out-you have to write down the lot number and other information. It takes several minutes with every single sample, and then a compliance officer comes by and checks our adherence with the documentation, which is always poor. So we get slapped on the wrist, and we've just said forget it, it's too time consuming, and we're just going to get in trouble. If you don't have any samples, the detail people don't bring demonstration devices either, so we don't see them and can't learn how they work or teach our patients. Then when the patients come in, they almost never bring their maintenance inhalers, but occasionally they'll bring the rescue inhalers, and maybe you can check their technique on that one. But you're also under a lot of time pressure. Most practitioners, as you pointed out, don't know how to do it, but they also don't have the time if they did. So whom do you rely on? We have a clinic nurse who is helpful, but she has time pressure, too, and also doesn't know about the newer devices. RTs are the ones in the best position because they usually have more familiarity than others, but they don't come to the out-patient clinics because nobody pays for their time. One opportunity is when these patients go home from the hospital, but then what they're using from the hospital formulary isn't the same as what they're using at home! You can teach them how to use what they're using in the hospital, but it's not relevant once they leave. We have all these systemic problems, and we're poorly organized...I'm frankly not sure how to get around it.

* MacIntyre: Nick, I share your concerns. One way we've been addressing it, although unfortunately for only an small percentage of patients, is the pulmonary rehab clinic. This is a magnificent place to reinforce these concepts over and over and over again. It does need to be repeated multiple times to finally get patients to get it right. I wish there was a way to expand that experience to more people than we currently do, but it is a model for how we might address the problem.

Hill: That's a great point. Of course, rehab programs are going out of business because of the problems with reimbursement. 
$\dagger$ Fink: With all the pressure on readmissions and cost in the hospitals and ultimately in the home, if you have $60 \%$ of your people who don't know how to use aerosol devices and patients don't get the benefit of the medication, hospitalizations go up, as you pointed out very nicely. So the question is, how do we put the money into the training and make the time available? It's as important to COPD as it is to asthma, and a very small percentage of people get training in either group. How do we make it a priority for the hospital? There are education current procedural terminology (CPT) codes that I believe cover 20 minutes, but it takes about 45 minutes for really good training. If people in practice say "every time you come see me, bring in ALL of your meds," they'll do it. One experience I had a number of years ago was at a Veterans Affairs (VA) hospital, and for all the concerns about how bad the VA might be, we had a unique situation where (maybe you have it in health maintenance organizations [HMOs]) you see the same patients in the emergency room (ER), on the floors, and in the out-patient clinics. So we made sure we gave the same training on devices when they're in the ER, where of course they don't remember anything while gasping for breath, but when they're feeling better, they might remember some of it. In the out-patient clinics, that's where they really reinforce with those return demonstrations, and they've really paid off. We documented over a 3-year period about a $60 \%$ reduction in terms of patients coming back to the ER and about a $60 \%$ reduction in admissions from the ER to the hospital. So I'm convinced—and it's anecdotal, I'm sorry-but I'm convinced that that type of training really makes a huge difference. And we need to figure out ways to do it as well as the VA does.

Hill: Despite the trashing of the VA system we've been hearing about recently, I agree that the VA does do some things better than the other systems.
Berlinski: I think there's probably a role for the associations and scientific societies to try to explain with all the data that are out there that it's for the patients' benefit that this education takes place, even if it might not be reimbursed. I think that it is very important to help administrators understand the value of this education. The data are there, so it's not a stretch; there are real data showing that if you don't know how to use your inhaler, you come more often to the ER.

Ari: I agree with you because I also believe that there is an important role for associations and scientific societies to improve patient education and adherence in aerosol medicine. With that being said, I would like to share my experience with the Turkish Respiratory Society (TRS), with which I have been affiliated since October 2010. The TRS has a networking group named the Inhalation Treatments Networking Groups (INTEDA). Experts in aerosol medicine, such as physicians, scientists, and health-care professionals, get together for intensive work to clarify issues, formulate strategies, and develop action plans to continuously improve current practices in aerosol medicine. Since its establishment in 2007, INTEDA has organized a variety of lectures, symposia, workshops, and educational programs on inhalation treatments not only for Turkish physicians and health-care professionals, but also for patients and caregivers in almost every state in the Turkish Republic. The group conducted 2 multi-center research projects. The first project explored the knowledge and opinions of Turkish physicians regarding aerosol therapy, and the second project determined the errors made in aerosol device use. Both projects received the first-place poster presentation award at the European Academy of Allergy and Clinical Immunology Congress in 2011. The TRS along with INTEDA established a call center and web site to streamline communication among all physicians and health-care professional interested in aerosol therapy. The call center is a first in the Turkish Republic, and patients' questions about inhalation treatments have been answered at no cost. The INTEDA members definitely go above and beyond expectations in improving patient education and adherence to prescribed inhaled medications, and I am very proud of being a part of this networking group.

Restrepo: One suggestion for societies would be that everyone who gets on YouTube can see educational videos for free. I think the problem now with most educational programs available is the cost, so you cannot train only the health-care providers, but also the patients and their families. They can also check out this device and how they have to use it. I think societies should make this available, and physicians and healthcare providers should inform their patients and provide the link to the YouTube page so that patients can inform themselves. This would be interesting.

Ari: Yes, the INTEDA group members, along with the support they received from the TRS, have prepared a web site that provides interactive patient education documents, information about aerosol delivery devices available on the Turkish market, and common mistakes that affect the efficacy of aerosol therapy. All the documents provided on the web site are free of charge to patients, physicians, and health-care professionals.

Hill: The concern would be what kind of information you get from YouTube. I'm sure many if not all of you have seen the "House" episode demonstrating inhaler technique. You know what I'm talking about? He asks her to demonstrate. She asks, "Doctor, do you think I'm an idiot?" He says, "No, but just show me." So she does 2 shots just behind her ears like a perfume. 


\section{Patient Education and Adherence to Aerosol Therapy}

Ari: I am familiar with the show you mentioned. Although it is funny, I still believe the same type of mistakes are possible in some patients with pulmonary diseases. I also agree with you about the inaccuracy of information that is available online. Everything that we see on YouTube is not accurate and reliable. Therefore, it is essential for scientific societies to prepare educational documents for patients, physicians, and health-care professionals to ensure continuous improvement in aerosol therapy. The American Association for Respiratory Care (AARC) and the TRS set good examples.

$\dagger$ Fink: Several organizations such as the International Society of Aerosols in Medicine try to do postgraduate programs at the American Thoracic Society (ATS), American College of Chest Physicians (ACCP) and other physician groups to educate physicians on how to use these aerosol devices and best methods of teaching their patients. The problem is that many physicians do not see the need to take time to learn these simple aero- sol devices. Many claim to know the guidelines on asthma and COPD including the use of aerosol devices so they are not motivated to take their limited educational time to learn about aerosol devices versus a program on juvenile diabetes, for example. The real issue is how to get people's attention to overcome that 8 year lag between the time a new device is introduced and the clinicians learning how to use it competently.

Restrepo: In our program, Dr Sandra Adams developed a nonprofit foundation called WipeCOPD, and she has extended it to other diseases. She trains all of our fellows and the faculty and brings all these devices for us to use for training. You then can understand the complexity of the problem and difficulties in getting these devices to function properly. You can really imagine what happens with a patient at home trying to do this. I think there are some other programs that are starting to look at this, but we haven't really understood the magnitude of the issues because all the companies are coming out with new med- ications, and they all have a specific device. The complexity will continue to grow.

Ari: The AARC has certainly taken an active role in patient education and adherence to aerosol therapy. I was honored to be asked to co-author "A Guide for Aerosol Delivery Devices for Respiratory Therapists," which is being translated into Turkish, Chinese, Spanish, Italian, and Arabic. The AARC also prepared 2 different guides, one for physicians and another for patients and their caregivers. All versions of this guide are available on the AARC web site free of charge.

* Neil R MacIntyre MD FAARC, Division of Pulmonary and Critical Care Medicine, Duke University, Durham, North Carolina, representing InspiRx.

$\dagger$ James B Fink PhD RRT FAARC, James B Fink LLC, San Mateo, California, and Division of Respiratory Therapy, Georgia State University, Atlanta, Georgia, representing Aerogen. 